NEWCOMERS AND FOOD INSECURITY:

A CRITICAL LITERATURE REVIEW ON IMMIGRATION AND FOOD SECURITY

by

Kristen Soo, B.A., University of Ottawa, 2010

\author{
A Major Research Paper \\ presented to Ryerson University \\ in partial fulfillment of the requirements for the degree of \\ Master of Arts \\ in the Program of \\ Immigration and Settlement Studies
}

Toronto, Ontario, Canada, 2012

(C) Kristen Soo 2012 


\section{AUTHOR'S DECLARATION FOR ELECTRONIC SUBMISSION OF A MAJOR RESEARCH PAPER}

I hereby declare that I am the sole author of this Major Research Paper. This is a true copy of the MRP, including any required final revisions, as accepted by my examiners.

I authorize Ryerson University to lend this MRP to other institutions or individuals for the purpose of scholarly research.

I further authorize Ryerson University to reproduce this MRP by photocopying or by other means, in total or in part, at the request of other institutions or individuals for the purpose of scholarly research.

I understand that my MRP may be made electronically available to the public. 


\title{
NEWCOMERS AND FOOD INSECURITY: \\ A CRITICAL LITERATURE REVIEW ON IMMIGRATION AND FOOD SECURITY
}

\author{
Kristen Soo \\ Master of Arts, 2012 \\ Immigration and Settlement Studies \\ Ryerson University
}

\begin{abstract}
In Canada, recent immigrant households are more likely to be food insecure than non-immigrant households. This is important for Canada, which receives approximately 250,000 permanent residents each year, as food security is linked to how immigrants perceive membership, reconstruct identity, and integrate successfully. Literature on immigration and food insecurity exists; however, it has not been collected or analyzed through an in-depth, critical review. This paper comprises the findings of a review of Canadian and international literature on barriers to food security for immigrants and their children. It includes sources from the academic, interdisciplinary literature in addition to government and non-government primary data, and considers the experiences of immigrants in terms of availability, accessibility, adequacy, acceptability, and agency of food. This review provides an understanding of the research that exists on the causes of food insecurity for newcomers, as well as identifies gaps in the literature and recommendations for further research.
\end{abstract}

\section{Key Words:}

Food security, immigration, settlement, Canada 


\section{ACKNOWLEDGEMENTS}

My thanks go foremost to God, whose grace and love for us through Jesus drives my motivation to serve immigrants and refugees.

Deep thanks to Mustafa Koç for your always patient guidance as supervisor, and to Iara Lessa for your encouraging comments as second reader.

I am so grateful to my family and friends, who have been such a source of support and prayer throughout this year. 


\section{TABLE OF CONTENTS}

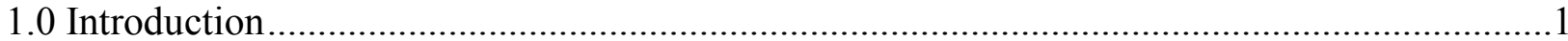

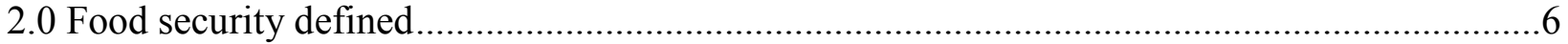

3.0 Review of literature on food security and immigrants........................................................

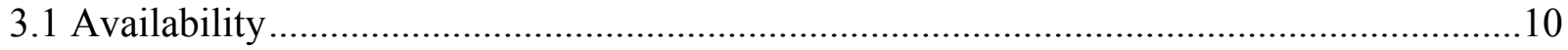

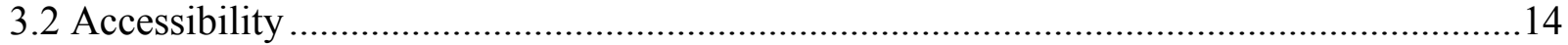

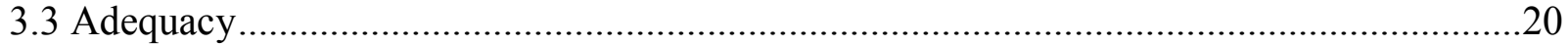

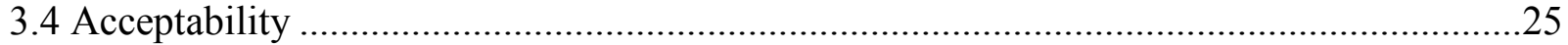

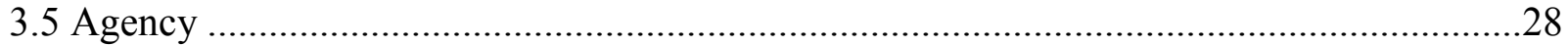

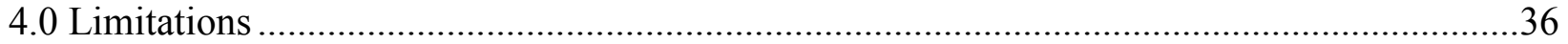

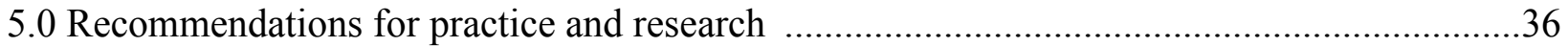

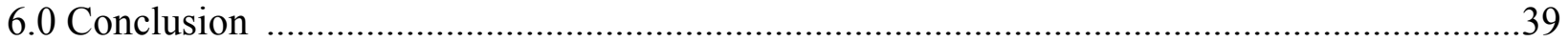

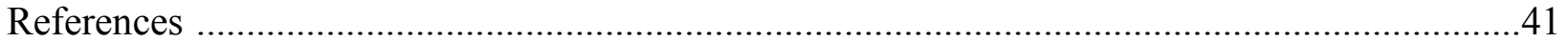




\subsection{Introduction}

The process of immigrating to and settling in a new country involves many life changes; one of the changes that is most apparent on a daily basis relates to food. What to eat, how much of it to eat, where to get it, and how much it costs are considerations for immigrants negotiating their way in a new environment and culture. This Major Research Project focuses on food security in the context of the immigration and settlement experience. It brings together and critically analyzes the literature on food security for immigrants with specific focus on Canada, and by doing so, seeks to build an understanding of what literature exists on the major barriers to food security for newcomers to Canada. The literature is analyzed in terms of the five components of food security: food availability, accessibility, adequacy, acceptability, and agency. While literature reviews have been conducted on food security, none have focused specifically on immigrants in Canada. This paper aims to fill this gap in the literature, as well as identify recommendations for practice and directions for future research.

Food insecurity for immigrants merits research for a number of reasons, including its influence on newcomers' identity formation and feelings of belonging in Canada; its association with discrimination, racism, and poverty; and its effect on immigrants' ability to integrate into and contribute to all aspects of life in Canada. The literature has noted the importance that food plays on identity, highlighting that food is both physical and symbolic: when we eat food, our bodies react to nutrients of the ingredients. At the same time, the food also conveys meaning to ourselves and others about who we are. Food can signal collective identity, allowing us to express our affiliations, and also allowing others to make associations about us (Kittler \& Sucher, 2004). Specifically for immigrants and their children, food can be a way to remain 
connected to their sending or ancestral culture, or to assert an acculturated identity (Valliantos \& Raine, 2008; Guendelman, Cheryan, and Monin, 2011).

Food security, and the factors that encourage or hinder it, are important for feelings of self-worth and belonging in society. Koç and Welsh (2002) point out that this is an area of concern for immigrants, who are starting in a new country and new circumstances:

For immigrants who go through a dramatic cultural and spatial transition, not only the familiarity of cultural experiences and consumption patterns, but also rights, entitlements and quality of life make important points of comparison between past and present, as these will have immediate effects on health and well-being of immigrants and their families (Williamson, 1998). When we talk about food and foodways, we need to examine, not only familiarity, but also accessibility as an issue of identity formation. The feeling of belonging or identification with the host society cannot be achieved without full membership or integration. For this reason, food security, like other basic rights, needs to be conceived as an important analytical tool in evaluating how immigrants perceive their membership, and reconstruct their identity and integrate successfully.... (p. 4)

In this way, food insecurity is not only about lack of food, but about broader economic and social circumstances that lead immigrants to the point of being food insecure. Newcomers experience food insecurity as a result of factors such as poverty and exclusion, pointing to issues of social justice and anti-discrimination. As Lessa and Rocha (forthcoming) note, "food relations are, like all social relations, marked by structuring forces that determine exclusions and inclusions within and among groups of people" (p.2). Without feeling like a full participant in society who is able to access all that is offered to locally-born residents, it is difficult for immigrants to feel at home, welcomed, or valued and be able to integrate into and contribute to Canadian society. Not only adults, but also children experience this sense of marginalization if they are not able to obtain sufficient food. Economically disadvantaged children "are often socially isolated, unable to take part in the same cultural food activities as their cohort group ... alienated in both the public and 
the private sphere, poorly fed children often experience a deep sense of social exclusion" (Harris \& Shepherd, 2007, p. 140).

Food insecurity can prevent immigrants from feeling like a fully participating member of society, and the health issues that can result can further reinforce this sense of marginalization and isolation. Food insecurity is linked to a number of serious health concerns, both physical and mental (McIntyre \& Tarasuk, 2002). Poor health and economic exclusion can create a vicious cycle, as "protracted employment/income insecurity and negative health exposures mutually reinforce each other in ways that lead to disempowerment and long-term deterioration of health" (Access Alliance, n.d.). Lack of income can lead to food insecurity, which can then lead to poor health. Poor health prevents immigrants from being able to obtain or keep gainful employment. And all of these factors contribute to immigrants forming feelings of exclusion from the receiving country.

Given the importance of food security to the immigrant experience, it is alarming that many newcomers are food insecure. The 2007 Canadian Community Health Survey, which was the most recent, comprehensive survey of food security in Canada, found that 7.7 percent or 961,000 of households in Canada were food insecure in 2007-2008. This means that 1.92 million people aged 12 or over lived in a food insecure household. Recent immigrants, however, have a higher likelihood of being in the food insecure group than non-immigrants. 12.6 percent of recent immigrant households - that is, households whose inhabitants have been in Canada for fewer than five years - are food insecure. This is high compared to the 7.5 percent of non-immigrant households and the 7.8 percent of non-recent immigrant households that reported they were uncertain of having, or unable to acquire, enough food to meet the needs of all their members because they had insufficient money for food (Health Canada, 2007). 
Food insecurity and the associated feelings of marginalization are concerning for a country that relies so heavily upon immigration. Immigration has played an important role in Canada's history in terms of building population and supplying workers, and today is still a major factor in the growth of Canada's population and economy. During the past century, over 13 million immigrants arrived in Canada (HRSDC, 2012). Since 1987, the number of permanent residents received in Canada has been consistently over 150,000, and in recent years, the number of permanent residents granted status has reached approximately 250,000 each year (CIC, 2010). Statistics Canada (2012) emphasizes the importance of immigration when it states that "without a sustained level of immigration or a substantial increase in fertility, Canada's population growth could, within 20 years, be close to zero."

According to the 2006 Canadian Census, 19.8 percent of the country's population was born outside Canada - the highest level since 1931. Close to 2 million people, or 6.3 percent of the total population in Canada, were immigrants who had arrived within the previous 10 years. Immigration has also ushered in a change in the ethnic composition of the population in Canada. Prior to 1961, the vast majority—90.5 percent—of immigrants were from Europe. More recent immigrants are more likely to come from countries outside of Europe; the majority come from Asia at 58.3 percent, versus 16.1 from Europe. In the 2006 Census, more than 200 ethnic origins were reported. Based on these figures, the government has acknowledged that "immigration is the most important component of Canada's population growth, and changes in the origins of new immigrants suggest that Canada will continue to be a diverse country" (HRSDC, 2012).

Immigration is not only important for Canada in terms of numbers of bodies that are added to the population, but also for the contribution that the individuals and groups make to Canadian society. Need for labour has historically been a driver for immigration and continues to 
be a priority (Kelley \& Trebilcock, 2010). Citizenship and Immigration Canada (2010a), the department responsible for setting immigration policy and levels in Canada, states that "within the next few years, Canada's labour force growth will depend on immigration. Welcoming immigrants with the skills we need is essential to build Canada's future labour force." Recently, Minister of Citizenship, Immigration and Multiculturalism, Jason Kenney, quoting Prime Minister Stephen Harper, stated in a speech that the government would "undertake significant reform of our immigration system [and] make our economic and labour force needs the central goal of our immigration efforts in the future" (CIC, 2012).

Based on this understanding of the importance of food security and immigration in Canada, this Major Research Paper reviews works from the rich literature on the topic. To locate relevant studies on immigration and food security, searches of online databases were conducted. The general multi-disciplinary search engine Google Scholar, general social science databases such as Proquest Research Library and Academic Search Premier, as well as more specialized databases on the topics of nursing, medicine, political science, and sociology (e.g., ProQuest Nursing \& Allied Health Source, PubMed, ProQuest Political Science, Social Services Abstracts) were searched.

The terms food security, food insecurity food environment, food supply, and food resources were used for searching. These terms were combined with the terms 'migra,' immigrant, emigrant, newcomer, refugee, and Canada. In all of the databases that accepted it, truncation was used on the search terms. The terms were used to search the titles, abstracts, and bodies of books, journal articles, government publications, and dissertations and theses. The date limit of 1996 onwards was applied to capture articles written after the World Food Summit which took place that year. 
The abstracts of the resulting articles were then read to determine relevance to the topic of the literature review. Only articles written in English were included. Articles that discussed causes of food insecurity for immigrants, were written about the period 1996 to 2012, and focused on countries that receive immigrants (Canada, but also the United States, Australia, and others) were included. Articles that discussed food and emigration/immigration in the same article, but not in relation to each other, or that did not discuss human populations (e.g., environmental/biological literature) were excluded. The bibliographies of the selected articles were then scanned for other relevant articles that met the date, language, and subject matter criteria. The resulting articles were then reviewed, analyzed, and sorted into the categories of availability, accessibility, adequacy, acceptability, and agency, which is a framework that has been set out by the Centre for Studies in Food Security and is used throughout the literature.

\subsection{Food security defined}

The conceptualization of food security has grown and developed over the years since it was first discussed in international development literature in the 1960s and 1970s (Toronto Public Health, 2006). A count conducted in 1992 showed that there were close to 200 definitions of food security in use (Maxwell \& Smith, 1993). At the World Food Summit in 1996, the largest gathering on the topic of food security, a definition was agreed upon by 182 countries in attendance and is now widely used throughout the literature, including literature considered in this review. According to the definition, food security exists "when all people at all times have access to sufficient, safe, nutritious food to maintain a healthy and active life" (WHO, 2012). This definition of food security has been adopted at high levels in Canada in documents such as Canada's Action Plan for Food Security, as well as by federal government departments 
including Health Canada and the Public Health Agency of Canada. The World Health Organization (2012) elaborates that "commonly, the concept of food security is defined as including both physical and economic access to food that meets people's dietary needs as well as their food preferences."

Beyond physical and economic access to food, scholars have recognized that food security encompasses a number of dimensions. It is often analyzed in terms of five components: availability, accessibility, adequacy, acceptability, and agency (Toronto Public Health, 2006). Availability refers to the sufficiency in quantity of food, while accessibility deals with the economic and physical aspects of obtaining food. Adequacy refers to the nutritional value and safety of the food, as well as the production methods. Acceptability concerns cultural preferences in food, and agency encompasses the policies and processes that enable food security (Centre for Studies in Food Security, 2012).

The World Food Summit in 1996 was a significant event as it marked the moment the global community affirmed food security as a human right, struck international consensus on activity to affirm that commitment, and agreed upon a definition of food security. At the Summit, held at the headquarters of the Food and Agriculture Organization (FAO) of the United Nations in Rome on November 13-17, 1996, the international community pledged to eradicate global hunger. Over the course of five days, highest-level representatives from 185 countries and the European Community, as well as representatives of inter-governmental and non-governmental organizations, discussed the challenge of eradicating food insecurity, which the FAO calls "one of the most important issues facing world leaders in the new millennium" (FAO, 1996). As a result of the discussion, representatives from 182 countries, including Canada, adopted the Rome Declaration on World Food Security and the World Food Summit Plan of Action. The core 
commitment of the Rome Declaration was to reduce by half the number of undernourished people in the world by 2015. The Plan of Action set out steps to achieve this goal.

At the Summit, it was requested that the right to food, which was previously recognized in the 1948 Universal Declaration of Human Rights and enshrined in the 1966 International Covenant on Economic, Social and Cultural Rights, be given more concrete and operational context (UN Special Rapporteur on the Right to Food, n.d.). The signatories of the Rome Declaration reaffirmed "the right of everyone to have access to safe and nutritious food, consistent with the right to adequate food and the fundamental right of everyone to be free from hunger" (FAO, 1996a). An authoritative definition of the right to food is offered by the Committee on Economic, Social and Cultural Rights in its General Comment 12: "the right to adequate food is realized when every man, woman and child, alone or in community with others, has physical and economic access at all times to adequate food or means for its procurement" (UN Special Rapporteur on the Right to Food, n.d.). Riches (1999) points out that while the right to food is not enshrined in the Canadian Charter of Rights and Freedoms, the Government of Canada has acknowledged the right to food in numerous international conventions and declarations, including the Rome Declaration.

Following the World Food Summit, the Government of Canada created Canada's Action Plan on Food Security. The Plan affirms the right to food, and sets out 10 priorities concerning domestic and international food security. In the domestic sphere, there were six commitments, which were to create an enabling environment for the eradication of poverty and for durable peace; implement policies to eradicate poverty and inequality, and increase access to food; pursue sustainable agriculture and rural development policies and practices; ensure that trade policies are conducive to fostering food security through a fair, market-oriented world trade 
system; be prepared for emergency food requirements in the case of natural or man-made disaster; and promote private and public investment into human resources, sustainable food, agriculture, fisheries, forestry, and rural development (Agriculture and Agri-Food Canada, 1998). The Plan acknowledges that recent immigrants are among the groups in Canada most likely to be affected by low incomes, which is a key barrier to food security for immigrants, but is far from a comprehensive explanation of the difficulties newcomers face. Canada's Action Plan on Food Security has not been seen as a success; there has been a lack of implementation in part because there is not a sole federal department responsible for it (Riches, Buckingham, MacRae \& Ostry, 2004; Koç, MacRae, Desjardins \& Roberts, 2008; Koç,\& Bas, 2012). Riches (1999) states that "clearly the domestic commitment to the right to food has been abandoned" (p. 204).

\subsection{Review of literature on food security and immigrants}

Past literature reviews related to food security have been conducted by government departments, consultants, and academics, though none have focused specifically on barriers to food security for immigrants in Canada. For example, reviews have covered the general topic of food insecurity and approaches to addressing it (Brink, 2001; Toronto Public Health, 2006;

Middlebrook, 2008; Bidwell, 2009). Other reviews have focused on conceptual issues, such as Maxwell and Smith's (1993) work that brings together concepts, measures, and indicators of food security; Maxwell and Wiebe's (1998) review of the concepts of land tenure and food security; and Dilley and Boudreau's (2001) work on the definitions of vulnerability in the context of food security. Others have focused on certain geographic areas or phenomena, such as food deserts (Beaulac, Kristjansson \& Cummins, 2009; Walker, Keane \& Burke, 2010), urban 
centres (Ruel et al., 1998; Ruel, Garrett, Hawkes \& Cohen, 2010), and low-income communities (Lawrence, 2007).

A number of reviews have also covered the food insecurity-obesity paradox (Burns, 2004; Dinour, Bergen \& Yeh, 2007; Larson \& Story, 2011). Policies such as food stamps and food security interventions in the United States have been the subject of other literature reviews (Fox, Hamilton \& Lin, 2004; Maryns, 2008). Slocum (2010) has conducted a literature review on food security, but with the focus on race, rather than immigrant status. A review by the Centre for Culture Ethnicity and Health (2008) in Australia does focus on immigrants, but specifically those that arrive under Australia’s Refugee and Special Humanitarian Program.

In reviewing the literature on food security for immigrants in Canada, this paper finds that the most severe problems faced by newcomers centre around accessibility—particularly economic access to food. Adequacy in terms of nutritional quality of the food is also an issue, as immigrants' diets change and often become less healthy. The issues with adequacy and acceptability are rooted in problems of agency: several policies and processes hinder immigrants' ability to stay out of poverty, and there is also a need for a national strategy that will encourage coordination between stakeholders and accountability for food security in Canada.

\subsection{Availability}

"In our countries we have food right there... For instance, my mother has everything in her backyard. She has peppers, tomatoes, eggplants, tallota [Dominican term for root vegetables such as yucca... all the vegetables she needs... and the fruit! The bananas [... ] when the children want bananas: 'let's go get some...there.' Everything is fresh." - Immigrant from Dominican Republic living in New York City (Park et al., 2011, p. 17)

A walk through any aisle at a grocery store in Canada's main immigrant hubs makes it abundantly clear that Canada is a land of plenty. Shelves and refrigerator cases are stocked high 
with everything from milk to meat to maple syrup. Why, then, in an environment so overflowing with food, are immigrants going hungry? While food is overall available, it is often not available in the areas in which immigrants have settled. The literature notes the problem of food desertslow-income, urban neighbourhoods that are characterized by their lack of access to healthy, nutritious food. Smoyer-Tomic, Spence, and Amrhein (2006) and Larsen and Gilliland (2008) are two of the few peer-reviewed studies that find food deserts in Canada, specifically in London, Ontario and Edmonton, Alberta. Other publications such as those by Lister (2007) and the Martin Prosperity Institute (2010) map food deserts in Toronto, Ontario. Other studies find that geographic proximity to supermarkets is not an issue for poor neighbourhoods in Canada: studies by Apparicio, Cloutier, and Shearmur (2007) and Bertrand, Therien, and Cloutier (2008) both do not find food deserts in Montreal, and Pouliot and Hamelin (2009) find that differences in access to fresh fruit and vegetable stores were not associated with deprivation but rather with rurality. Behjat's (2012) study of Toronto highlights that whether food deserts are found to exist will vary depending on the methodology used.

The Canadian literature on food deserts does not directly discuss immigrant status or ethnicity in relation to food deserts, marking a gap that future studies can fill. Literature on ethnic enclaves can be drawn on here to inform the discussion. The defining characteristics of Canada's ethnic enclaves are that they have an ethnic concentration and are institutionally complete, in that they feature ethnic businesses, institutions, associations, and services (Qadeer, Agrawal, and Lovell, 2010). This means that immigrants who opt to live among co-ethnics in enclaves will have access to local ethnic businesses, including grocery stores.

The prevalence and nature of both food deserts and ethnic enclaves in Canada are markedly different from those in the US or UK, making it difficult to draw comparisons 
(Friendly, 2008). It can be noted that literature in the US, however, suggests that living in lowincome, immigrant neighbourhoods is protective in that there is often greater access to healthy, fresh foods (Anchondo, 2010; Puhl, 2011).

Other US studies by Dubowitz et al. (2007) and Chaufan, Constantino, and Davis (2012) indicate that there was access to food in the neighbourhoods in which the immigrants who were studied lived, but that the choice was between commuting for long periods of time to access lower priced foods, or paying more in stores that were located closer to home. So while scarcity of food and physical access to food purchasing points were not considered problems by the respondents, the indirectly related issues of high prices of healthy food close to home, limited time for shopping, and arranging transportation and childcare were challenges. Likewise, Kirpatrick and Tarasuk's (2010) Canadian study found that geographic access to a budget supermarket did not mitigate food insecurity. They state that:

Our results suggest that the demands associated with grocery shopping for poor families are more complex. Despite the apparent adequacy of food retail access in most neighbourhoods, over half of the families in the present study incurred transportation costs, presumably because it was too difficult for them to carry their groceries home on foot. (p. 1145)

This highlights that, for immigrants, whether living in a food desert or not, transport, time, and price, not simply geographic proximity, are considerations.

Not only the neighbourhood, but also the type of dwelling affects whether immigrants have food available. Immigrants comprise a high proportion of residents in the high rise apartment buildings in Toronto's inner suburbs, as has been examined through the United Way's Vertical Poverty research series (2011). At times, a dense population of immigrants from a common ethnic background living in a high rise complex can be beneficial for food availability: Ghosh (2012) studies the dynamics of the lives of Bangladeshi immigrants who live in high rise 
buildings in low-income neighbourhoods in eastern Toronto or Toronto's inner suburbs. Ghosh finds that the immigrants who live in these buildings have subversively converted units in the building into Bangladeshi grocery stores. As the women who live in the building do not have to leave the residential building during winter to do groceries, and as shoppers are recognized by the shop owner creating a sense of community, the immigrants find this preferable to shopping in the nearby discount supermarket or other stores. On the other hand, by virtue of living in dense, high rise apartments, residents do not have backyards in which they can grow their own food as an alternative to buying it at the grocery store (Baker, 2005).

Beyond grocery stores, community gardens and kitchens can act as a source of fresh food for immigrants, especially for those who do not have access to backyard gardens. Baker's (2005) case studies of three community gardens in Toronto, Ontario highlight that community gardens are important for immigrants to achieve food system localization, but also bring a slew of benefits related to other aspects of food security such as acceptability and agency. Community and collective kitchens offer social and personal benefits to users, but whether they actually lead to increased food resources is questionable (Crawford \& Kalina, 1997; Tarasuk \& Reynolds, 1999; Engler-Stringer \& Berenbaum, 2005). Engler-Stringer \& Berenbaum (2005) call for more information on subsidies available and amount of food cooked to be included in future studies of collective kitchens, which would allow for clarification of the extent to which participation in these programs leads to greater amounts of food for users.

Good Food Boxes (GFB) are another effective method of distributing fresh produce to areas that lack affordable or accessible options. Produce — with emphasis on in-season and nutritious goods - is bought in bulk and divided among boxes which are then delivered to central pick up points. This is an innovative means of bringing fresh, nutritious produce to areas that 
may not have convenient or well-priced fruits and vegetables. Clients pay for the boxes, but the boxes are subsidized, which brings costs down while maintaining dignity in the process (Scharf, 1999). Empowerment and dignity are themes that are prevalent throughout the literature on community gardens, community kitchens, and Good Food Boxes.

\subsection{Accessibility}

"For our food, we are trying [...] to get the very cheap food to save the money for rent or for electricity bill or for other things. " - Immigrant living in Edmonton (Gurnett, 2008, p. 101)

Accessibility, particularly economic access, represents the greatest challenge to food security for immigrants in Canada. Financial ability to obtain food is a necessary condition for food security, and this is a particular issue for immigrants who face difficulty in securing gainful employment once arriving in Canada. Low socio-economic status is not a barrier to food security unique to immigrants; the same income-related factors that hinder immigrants from attaining food security can also hinder the general population. Immigrants, however, face challenges above and beyond those experienced by the Canadian-born population in gaining income. Recent immigrants have been described as facing "a particularly complex set of circumstances" with respect to securing employment in Canada (Che, 2009, p. 37). When trying to find employment, despite their comparable education and training, immigrants may have difficulty having their credentials assessed due to the high cost of attending post-secondary institutions or a lack of retraining or accreditation programs for certain professions. Employers may be unwilling to hire newcomers due to lack of Canadian experience. Cultural differences can contribute to not being aware of or knowing about how to access social support services. Racism, discrimination, and prejudiceincluding the stigma that immigrants are taking away jobs from Canadians - all act as challenges for immigrants to gain employment and income. Due to such factors, immigrants have been 
"expressing a growing sense of frustration, even despair, at the barriers they encounter to full participation in all domains of Canadian life" (Omidvar \& Richmond, 2003, p. 15). Immigrants do, however, benefit in comparison to the Canadian-born population in at least one aspect: were it not for immigrants' greater propensity to draw from savings and rely on family in times of economic hardship, Husbands (1998) suggests that food insecurity for recent immigrants would be much more severe.

These difficulties that immigrants face with securing employment and income lead to financial challenges in accessing food. Studies by Vahabi et al. (2011) and Rush et al. (2007) both indicate that recent immigrants of Latin American origin, despite high levels of education, experienced food insecurity due to income-related factors. Income and length of residence in Canada were reported to be inversely related to food security, and use of social assistance as main source of income, use of food banks, and limited English language proficiency were strong predictors of food insecurity. The same factors were found to play a role in food security among immigrant food bank users in a study by Kirkpatrick and Tarasuk (2010). Finding that socioeconomic status is linked to food security may not be surprising, but Kirpatrick and Tarasuk (2010) note that the degree of its severity means there is cause for concern: "the finding of higher odds of food insecurity with declining income is intuitive given that, by definition, food insecurity is related to inadequate financial resources to obtain adequate food. However, the fact that we were able to observe this relationship even in a low-income sample speaks to the potency of this effect" (p. 1144).

International literature points to similar trends. In research on refugees in Australia's humanitarian program, several scholars have reported that causes of food insecurity included a mix of income-related factors such as large household bills (e.g., purchasing furniture), welfare 
payments being received late, lack of budgeting skills, large medication bills, low income, shame over using emergency relief services, inadequate access to emergency relief, and lack of nutritional requirements from food banks (Burns, 2001; Gallegos, Ellies \& Wright, 2008; O'Reilly, O'Shea \& Bhusumane, 2012). Lower education, income, employment status, and participation in the Food Stamp program were found to be associated with food insecurity for not only refugees, but also their children among West African asylum seekers and resettled refugees in the US (Hadley \& Sellen, 2006; Hadley, Patil \& Nahayo, 2010).

While not the sole focus of any studies on immigration and food security, the obligation to send money back to family in immigrants' sending countries is discussed as an additional drain on immigrants' already limited budgets for food. Gallegos et al. (2008) noted that sending money "home" is a reason that refugees in Australia ran out of food and Sano, Garasky, Greder, Cook, and Browder (2010) found that for Latin immigrants in the US facing fragile food security or food insecurity, sending remittances to extended family in Mexico was a factor for their food security status. Immigrants often face a dilemma as to whether they should share their resources with extended family in their home country or keep the resources for their immediate family in the receiving country, and must use techniques to negotiate this dilemma. Worby's (2010) study indicated that the sample of Zimbabwean immigrants chose to remain out of communication from family members, while Quandt et al.'s (2006) work noted that immigrants will opt to provide food for family members they are with and postpone remittances. In Canada, 29 percent of immigrants in the 2000-2001 cohort had remitted in the approximately two to four years after landing, contributing an average of 3 percent of their annual pre-tax household income. Immigrants in Canada who were employed were more likely to remit than those who were working part time or are not in the labour force, but their employment status was not correlated 
with the amount remitted (Houle \& Schellenberg, 2008). This remittance behaviour and its implications for immigrants' food security in Canada are areas future studies can explore.

Lack of affordable housing exacerbates the problem of food insecurity for immigrants. Immigrants, compared to the overall population, are more likely to spend more than 30 percent of household income on housing. Spending 30 percent or less of household income on housing is considered affordable. About 23 percent of all Canadian households spend more than 30 percent on housing, but more than 80 percent of new immigrants spend more than 30 percent of their income on housing (Canada Mortgage and Housing Corporation, 2007; Preston et al,, 2011). For 30 percent of asylum seekers, housing takes up more than 75 percent of their household income. The struggles with unaffordable housing persist among immigrants who have been in Canada for five to 10 years (Preston et al., 2011). The problem of affordable housing is directly linked to food security: the cost of rent is fixed and must be paid every month, while food intake can be adjusted. This means that often, it is a choice between eating a meal and paying rent on time. Kirkpatrick and Tarasuk (2007) summarize the situation in the poignant phrase "pay the rent or feed the kids,' and note that this phenomenon is "well documented in in-depth studies of food insecurity" (p. 1465).

In Ontario, the problem of high rents is rooted in policy: the introduction of the Tenant Protection Act in 1998 meant that landlords could more easily raise rents, which led to a 20 percent spike in rent between 1998 and 2002, as well as an 8 percent increase in food bank usage in the same time period. While government-subsidized housing offers benefits such as location and services, it does not necessarily translate into more income after rent, as welfare payments are reduced if people live in subsidized housing, of which there is a limited stock. In terms of food bank usage, there is not a significant difference between food security for residents of 
subsidized housing and market rate housing (Daily Bread Food Bank, 2011). Husbands (1998) notes that the problems of rent and inadequate social assistance is particularly pronounced for newcomers.

For immigrants, race, ethnicity, class, and gender also matter in access to housing. Hulchanski (1997) argues that if there are barriers to access to housing, education, employment, or income - necessities of daily life — the settlement process will not be smooth. The result is differential incorporation, that is, unequal treatment and access to all aspects of society. So while the formal criteria for market rent housing is ability to pay, and for social housing is ability to meet various definitions of need, there are a number of primary and secondary barriers to attaining suitable housing. The primary barriers are those that are unchangeable over time: skin colour, ethnicity/culture/religion, and gender. Secondary barriers, which can and often change over time, include level and source of income, knowledge of housing system, language/accent, household type and size, knowledge of institutions and culture, and experience with dominant institutions and culture. Immigrants must not only deal with discrimination in obtaining employment, but also housing.

Even if not renting, buying property can strain budgets, leaving little money for food. Compared to others, many immigrants attain homeownership relatively short time period, indicating that they are either using the savings they bring to Canada, or are spending a very high proportion of their monthly income on mortgage payments (Hiebert et al., 2006; Murdie 2010). This homeownership comes at a cost, as immigrants sacrifice the money that otherwise could be used for food (Murdie, 2010).

Faced with a lack of employment or low income, immigrants may turn to social assistance, but this still may not be adequate for both food and other expenses such as housing or 
medication. Canada's large food banks have called for improvements to both social assistance and employment insurance, as a large proportion of food bank users rely on these sources of income (Food Banks Canada, 2011; Daily Bread Food Bank, 2011). The effects of the recent economic recession have been exacerbated by the fact that social assistance and Employment Insurance are more difficult to access now than in the previous 30 years. This means that people currently using social assistance have to survive on less income than during previous recessions, and so lack the ability to purchase basic necessities such as food (Daily Bread Food Bank, 2011). For some newcomers, social assistance may be the only available source of income, for example, asylum seekers who have not yet received a work permit. Furthermore, the cost of food is increasing faster than inflation and at a greater rate than the amount of social assistance allotted per recipient, which ranges from as low as $\$ 6,696$ per year for a single employable person in New Brunswick to the highest $\$ 41,818$ in Nunavut (National Council on Welfare, 2012). Therefore, social assistance is not sufficient for immigrants to be able to access adequate food and puts immigrants in a precarious situation. The Daily Bread Food Bank warns:

The growing gap between food costs and social assistance rates will spell disaster for those trying to eat enough to maintain health and well-being. It will also potentially spell disaster for the province, which could see increased levels of poverty- and nutritionrelated illnesses put greater strains on the health care system. (2011, p. 7).

There are yet other immigrant groups, such as temporary residents and undocumented immigrants that are not eligible to receive social assistance at all. While it is beyond the scope of this paper to examine groups with temporary or precarious status such as migrant workers, the economic challenges of these groups in Canada are documented in the literature (e.g., Goldring, Berinstein \& Bernhard, 2009; Walia, 2010). Some literature focuses on the elevated risk undocumented workers face of being able to access sufficient food due to ineligibility for social assistance, as well as other factors. For example, Standish et al. (2010) found that undocumented 
Mexican immigrants in New York City experience extremely high household density, and that the likelihood of higher household density is associated with food insecurity. Undocumented migrant farmworkers in Georgia, USA, are more likely to be food insecure than those with visas (Hill, Moloney, Mize, Himelick, \& Guest, 2011). In the US, undocumented immigrants are not be able to access Food Stamps, but are able to access child food programs, so Chávez (2007) emphasized that these programs should be of high quality. Canada does not use a Food Stamp system; food banks are one of the main safety nets for people finding themselves short of funds and in need of food. However, undocumented immigrants in Toronto were reported to be concerned about food security, and could not access food banks due to lack of status (Campbell, 2011).

\subsection{Adequacy}

"Well, we always have chocolate in the fridge here, and we store cakes that the food bank gives...these foods are just so available." - Immigrant woman in British Columbia (Bayanzadeh, 2008, p. 44)

With struggles around income come issues with adequacy of food for immigrants. As large portions of the household budget are allocated towards housing, little money is left for food. Often, inexpensive and unhealthy food ends up on the dinner table. Burkot, Burr, and Lac (2009) note the difficulty of eating a healthy diet, especially on a limited budget: "we're supposed to eat vegetables, drink milk, grill lean meats and lightly spread non-hydrogenated margarine on whole-grain toast. But it's not cheap. For many families, a diet of this nutrient-dense, healthy food is simply too expensive" (p. 84). The authors calculate that in some centrally located neighbourhoods in Toronto, which also have large immigrant populations, households would 
need to spend on average 19.8 percent of their income to purchase healthy food according to the Canada Food Guide.

The adjustment to the types of foods available in Canada — which are often less healthy than the foods from immigrants' sending countries - is another contributor to unhealthy eating for newcomers. This change in dietary patterns, called dietary acculturation is "the process that occurs when members of a minority group adopt the eating patterns/food choices of the host country" (Satia, 2010, p. 220). The literature suggests that this is a dynamic, non-linear process: rather than moving straight along a continuum from traditional to acculturated dietary choices, immigrants will often find new ways to use traditional foods, exclude certain foods, and introduce Western foods into their diets. This can result in a "bicultural diet," as Bayanzadeh (2008) found among Farsi and Dari-speaking women in British Columbia; it is also called an integrated diet, as Kwok (2006) found among Chinese immigrants who ate both acculturated, Western foods and traditional Chinese foods.

The process of dietary acculturation is influenced by the interaction between demographic/individual factors, social and economic factors, ethno-cultural norms, and exposure to the host culture (Satia, 2010). According Satia (2010), demographic/individual factors include age, gender, education, employment status, language, religiosity, and household composition. Social and economic factors would be education, income/purchasing power, food availability and accessibility, number of children in the home, living with an older relative, and place of residence, while ethnocultural norms include health beliefs, social integration and cohesion, shopping practices, social support. Finally, factors related to exposure to the host culture would include access to traditional media, peers, and access to traditional supermarkets. Sociodemographic factors such as length of residency, generation, and ability to speak and read 
English also come into play with changes in immigrant eating patterns (Varghese \& Moore-Orr, 2002). Food quality and time needed to prepare foods were also factors that have been found to influence dietary change (Varghese \& Moore-Orr, 2002; Satia, 2010).

Dietary acculturation has been shown to have negative effects on immigrants' health, because the styles of food available in high-income countries like Canada tend to be more energy-dense, and include processed foods and high levels of animal products. Acculturating to a Western diet also usually means a decreased intake of fruits, vegetables, and whole grains, and an increase in snacking and eating away from home. This, which is often coupled with lower physical activity, is the nutrition transition that has occurred in developed countries such as Canada, and is now also occurring in developing countries. The outcome is higher rates of obesity and other chronic diet-related diseases such as hypertension, cardiovascular disease and diabetes (Bayanzadeh, 2008). Whether this results in changes to Body Mass Index has been seen to depend on the immigrant group (Setia, Quesnel-Vallee, Abrahamowicz, Tousignant \& Lynch, 2009).

Not all immigrants will acculturate their diets at the same pace or to the same extent, and the health consequences of the dietary changes will vary. Indeed, much of the research on this topic focuses on one specific immigrant ethnic group, or compares changes between groups, and the reasons why and ways in which their diets acculturate. Among Chinese immigrants in the US and Canada, breakfast was the first meal to be Westernized due to convenience (Satia et al., 2000). Their consumption of all seven food groups increased, as well as their consumption of Western foods, while intake of traditional Chinese foods dropped (Lv \& Cason, 2004). It is not only the types of foods that change with acculturation, but also the portion sizes and where the food is from: Chinese immigrants who lived in Canada the longest ate significantly greater 
portion sizes, dined out more often, and consumed convenience foods more frequently

(Rosenmöller, Gasevic, Seidell \& Lear, 2011). Younger, highly educated immigrants who have lived longer in the US, and especially women with jobs outside the home had the most acculturated diets (Satia et al., 2001; Oster \& Yung, 2010). Chinese media, friends, and family were the main sources of nutrition information (Satia et al., 2000; Kwok, Mann, Wong \& Blum, 2009).

Looking towards immigrants from other parts of Asia, the dietary acculturation of Hmong immigrants born in US or in Thailand or Laos was influenced by age at immigration, length of residency in the US, and use of food assistance programs. Some families prepare two different evening meals: one of Hmong food for the parents, and one of American food for the children (Franzen \& Smith, 2009). Park, Paik, Ok, Skinner, and Spindler (2003) found that families of more acculturated (according to a scale the authors developed) Korean mothers preferred more Western foods: they dined out more, had lower preference for traditional Korean foods, and the mothers prepared fewer traditional Korean foods at home — as the traditional Korean diet is low in fat, the authors noted that it is logical to assume families of more acculturated Korean mothers were consuming higher levels of fat than families of less acculturated Korean mothers.

Latin American immigrants have also demonstrated dietary acculturation. Compared to Mexican women born in Mexico, Mexican-origin women born the in the US living in a Texas border town consumed more sugar-sweetened beverages and fast food meals (Sharkey, Johnson \& Dean, 2011). Dave, Evans, Saunders, Watkins \& Pfeiffer (2009) found that higher rates of acculturation as well as food security were associated with lower fruit and vegetable intake at Latino immigrants' homes. In their systematic review of the literature, Ayala, Baquero, and 
Kilinger (2008) cover several other studies about Latin American immigrants and dietary acculturation.

For Somali refugees, living in the country of immigration for four or more years and having English language proficiency were associated with intake of snack items (Dharod, Croom, Sady \& Morrell, 2011). In a study with Liberian and Bantu refugees, Patil, Hadley, and Nahayo (2009) note that children are often a strong influence over the dietary acculturation of their caretakers. Children attending daycare or school will have the opportunity to learn English and interact with children of the receiving culture. Their caretakers, however, will often be working in jobs such as cleaning at a hotel which does not allow for as many opportunities to interact with peers and learn English. English-language advertising then has a greater effect on the children, and as the children now have more advanced English language skills, the caretakers may trust them more with providing information about foods, which means more purchasing power for the children. As an added dimension, a study by Delisle (2010) noted that the traditional diets of African immigrants in three different countries were healthier than Western diets, and called for promotion of traditional dietary patterns, but warned that this may be difficult, as traditional foods tent to be disparaged, while urban, Western, or imported foods tend to carry more prestige.

Based on the findings, recommendations for practice in the literature include promoting the consumption of healthy traditional foods over Western options (Satia et al., 2000; Delisle, 2010). Other scholars call for education about both Western and traditional eating patterns (Park et al., 2003). Yet others add the nuance that nutrition information should be tailored according to the level of acculturation. For example, Lv and Cason (2004) recommend that more-acculturated Chinese-American immigrants should be encouraged to decrease the amount of fats, sweets, and 
soft drinks in their diets, while less-acculturated immigrants should be encouraged to maintain their healthy traditional diets and increase their consumption of fruits and vegetables. Additionally, nutrition information resources should be culturally-specific and -sensitive and take into consideration the environment (Satia-Abouta, Patterson, Kristal, The \& Tu, 2002; Varghese \& Moore-Orr, 2002; Dave et al., 2009). There is also a need for further research into how nutrition interventions would vary according to immigration class, for example, approaches may be different for refugees compared to economic immigrants (Patil, Hadley \& Nahayo, 2009).

\subsection{Acceptability}

"On Sunday, when we were at our home, we were very happy. We were reminded of our country and our meals together. There's a store here on Danforth that has fish. It is fresh and tastes very, very good. And so when we brought fish from this store... we prepare in our home and its very good taste. So those are those small things that remind [us of] our country or make me feel a little bit..." - Recent immigrant woman from Hungary living in Toronto (Lessa \& Rocha, 2009, p. 151)

While immigrants may choose to incorporate more Western foods into their diets, acceptability of food is still a consideration. Cultural acceptability, in terms of food choices and the way the foods are sourced and prepared, is an important aspect of food security for immigrants. Food plays a central role in formation and expression of identity, and so if it is difficult to access food that suits immigrants' tastes or dietary requirements (for example, for kosher or halal ingredients), it can be frustrating and alienating. A study conducted by Welsh (1998) and colleagues indicated that most of the participants, who were immigrants and people who serve immigrants, reported that finding familiar, culturally acceptable, and fresh foods was important. Local retail outlets and supermarkets in ethnic enclaves were a source for some specialty items, 
but other items, such as halal foods were reported to be harder to find and more expensive. Fishing was noted as meaningful for both diet and social interaction. Freshness of fruits and vegetables, unfamiliarity with frozen foods, quality of meat, and fat content were sources of complaint. An added challenge was understanding food labels, which participants found to be unclear and difficult to compare, but that the authors note are important for immigrants to be able to learn about the nutritional value of "new" ingredients (Welsh, 1998).

Everything surrounding the acceptability of food is profoundly connected to identity, and for immigrants who are undergoing a process of uprooting and putting down new roots in Canada, this is particularly salient. Lessa and Rocha's (2009; 2012) interviews with immigrant women demonstrated that food can be used to give concrete form to the nostalgic longing for home and offers what they call "diasporic healing." Food is used as a reminder of home, missing a certain food is a way to talk about missing home, and cooking and eating a certain food creates a sense of comfort and erase time and distance. Food can also be used in the process of othering and exclusion, as is the case when food is prohibitively expensive. This is deeply marginalizing, and as a result, many of the women interviewed managed costs by substituting ingredients, travelling for long times to find better prices, and spending time studying ads. In addition, marginalization takes place when husbands and children who bring food to work and school respectively become the subject of jokes, shaming, discrimination, and segregation. The authors note that ethnic foods are often not welcomed into mainstream society, despite the rhetoric of multiculturalism. At the same time, food can create positive interactions with the receiving country, for example, when an immigrant woman discovers new ingredient and creates an integrated recipe, thus creating a hybrid space in the home that helps mitigate against the hostility faced outside: "offering favourite traditional foods, unique hybrid dishes and surprising 
new foods can transform the home into a distinctive space that exists in the present but also in the re-lived experiences evoked by the tastes of the homeland" (Lessa and Rocha, 2009, p. 153). Preparing food in the home is also often chosen over eating in restaurants due to concern over ingesting prohibited foods. "I have to cook everything at home because of the Halal factor" noted one of the interviewees in Valliantos and Raine's (2008) study of South Asian and Arabic women in Canada. This is a consideration for Muslim and Hindu immigrants, as well as other immigrant groups, who have cultural or religious proscriptions against certain foods or preparations.

Similar findings are echoed throughout the literature. The themes in Lessa and Rocha's (2009) work are extended by Paul (2009) to 1.5- and second generation post-secondary students in Toronto, who also expressed that food is used to express longing, to marginalize, and to identify with Canadian culture. Second generation Asian students at two US universities are the subject of Guendelmann, Cheryan, and Monin's (2011) study, which found that food choices are a way to distance themselves from their Asian identity and express American identity: when their American identity was challenged, the students were more likely to select a Western food as their favourite.

Constructing identity through food, remembering home, and transmitting culture through food choices is a theme that recurs throughout the literature, often in studies that focus on immigrant women, as women tend to be responsible for food preparation in the home context and shopping and therefore influence their family members' nutrition and eating behaviours (Bayanzadeh, 2008). Muslim and Hindu women have the primary responsibility for ensuring that their families are following food proscriptions and that suitable food, prepared through appropriate methods, is offered (Valliantos \& Raine, 2008). Even outside of food behaviours set 
out by religion, mothers play a role in influencing whether their children prefer traditional or more Western foods, as demonstrated in Bowen and Devine's (2011) study of Puerto Rican girls.

Steps are being taken towards increasing access and sustainability of ingredients that immigrants wish to eat. The innovative World Crops Project is a collaboration between several different organizations in Ontario. The aim is to grow world crops - products that are in demand by the Greater Toronto Area's ethnically diverse population - locally, rather than importing them from international growers. In addition to offering a host of environmental and social benefits, this model reduced the distance from farm to fork and increases the freshness of the crops, and freshness has been expressed in the literature as important to immigrants in their food choices (Park et al., 2011). The world crops are currently being grown in urban gardens around the Greater Toronto Area, as Ontario has an ideal climate for many different types of fruits and vegetables (World Crops Project, n.d.). This project began in 2011, so is still very new; evaluation of the impact of the project on immigrants' access to fresh, culturally preferred fruits and vegetables is a future direction for research that should be explored. Additionally, future studies could track the extent to which these crops to influence the diets of other groups, including Canadian-born populations and immigrant groups who would not traditionally use these crops, but who may benefit from being able to consume more fresh fruits and vegetables made available through the project.

\subsection{Agency}

"...in my neighbourhood, there is a collective kitchen on Tuesday afternoon.... if my Fall semester's schedule fits, if by any chance we have time on Tuesday afternoon, okay we can go! But if my winter semester's schedule doesn't fit anymore, in winter we can't eat anymore [through this means]!" - Single mother and full-time student in Quebec City (Hamelin, Mercier \& Bédard, 2011, p. 60). 
The policies and processes that enable food security can be considered through the lenses of two approaches: the antipoverty approach and the sustainable-food-systems approach to food security (Power, 1999). The antipoverty, or social-justice, approach is rooted in the notion that Canada has enough available food to feed the population, and that the problem lies in lack of access to that food. And as Canada is an industrialized nation with a market economy, and most residents buy almost all of their food, this approach looks at lack of money to buy food. Power (1999) notes that:

The antipoverty approach to food security is inseparable from macroeconomic and socialpolicy analysis, for example, high rates of unemployment, the polarization of the job market into 'good' and 'bad' jobs, minimum wages well below the poverty line, inadequate welfare benefits, high costs of housing, regressive taxation policies, offloading of social programs to communities, and the unequal distribution of wealth.... The antipoverty approach is concerned with income security, rather than food and food security per se." (p. 31).

One of the main policies of concern in this approach to promoting food security is the social security system. The Canadian social security system was established following the Great Depression. In 1981, the first food bank was opened in Edmonton, Alberta, and the number of food banks across the country grew rapidly, as did usage of this service; food banks were the predominant response to food insecurity during the 1980s and 1990s. In 2011, 11.4 percent of food bank users surveyed by Food Banks Canada were recent immigrants or refugees (Food Banks Canada, 2011). Riches (2002) argues that this rise in the number of food banks indicates failure on behalf of the government: "the rise of food banks in Canada is concrete evidence both of the breakdown of the social safety net and the commodification of social assistance. As such, they undermine the state's obligation, as ratified in international conventions, to respect, protect and fulfil the human right to food" (p. 648). 
The difficulties immigrant face in obtaining income would be addressed by the antipoverty approach. Problems related to food security in terms of economic accessibility, including the myriad troubles immigrants face in securing employment, and the sufficiency of social assistance discussed earlier in the present paper, are all problems of poverty. Under this approach, the government would bear the main responsibility for addressing the root causes of poverty and thereby food insecurity. Toronto's food bank has called for a significant overhaul to the income security system, including employment support, social assistance, housing benefit, and disability benefits (Daily Bread Food Bank, 2011). Food Banks Canada (2011), the national charitable organization that represents and supports food banks across Canada, has also advocated for improvements to social assistance, as well as investments in affordable housing, protection of vulnerable seniors, updates to Employment Insurance, support for disadvantaged workers, investment in early learning and childcare, and maintenance of a strong Canada Social Transfer of funds from the federal government to provincial.

Regulatory organizations in their policies towards foreign credentials, and employers themselves in their attitudes and actions in disseminating information and hiring fairly, also play a role in alleviating the causes for poverty among immigrants. Scholars have called upon the Canadian government to work together with professional regulatory bodies, educational institutions, assessment agencies, trade unions, employers and service providers to make the process of foreign credential recognition more effective (Teelucksingh \& Galabuzi, 2007). The Daily Bread Food Bank (2011) has urged that:

There also needs to be more support for those who can attain more long-term, sustainable employment, as opposed to being forced by the system to accept any job. Otherwise, people will find themselves back on the system numerous times. The increasing trend of those with higher levels of education coming to food banks speaks to the need for employment supports other than resume writing or job searching, particularly for highly educated and skilled newcomers. (p. 22) 
English and French language proficiency requirements for immigration to Canada were recently increased, which some have hypothesized will change the composition of Canada's immigrants: they predict it will decrease the number of racialized immigrants from countries such as China and increase the number of immigrants from the English-speaking world (Friesen, 2012). Such immigrants would likely face fewer barriers related to language and racism in securing employment, which may reduce the number of immigrants who find themselves in poverty, though this does not address the root problems of prejudice and discrimination that act as barriers to economic opportunity and food security for current, racialized immigrants.

The second approach to promoting food security is the sustainable-food-systems approach, which sees "corporate control of the food system and the commodification of food [as] the predominant threats to food security" (Power, 1999, p. 33). The environmental movement has added that this capitalistic food system is unsustainable, as it disregards threats to human living standards and well-being as well as environmental degradation. Food projects under this approach have been implemented in Canada and the US. Power (1999) notes that the projects are of two major types: "first, the creation of alternative supported agriculture, and second, 'selfprovisioning' activities, including people's growing, preserving, and preparing their own food, often in collaboration with others working in community gardens and kitchens. These ways of feeding the hungry are seen as affording the poor more dignity than does charitable food distribution" (p. 33). Community gardens, collective kitchens, and the World Crops Project would all fall under this approach; these projects are mainly the domain of community organizations, though can be strengthened by the support of various levels of government.

Power (1999) argues that the sustainable-food-systems approach is not adequate to address food insecurity among Canada's poor for several reasons. First, the idea of community 
that these programs are based on is faulty because such community does not exist anymore in urban settings, and it ignores power relations and those who do not belong, such as immigrants. Secondly, food programs for the poor tend to blame the victim rather than the socio-economic conditions that led to the poverty, and the programs create a two-tier system of those who participate in the market based economy and those who must use a subsistence system. Third, the sheer number of food insecure people in Canada requires high levels of resources to operate and maintain programs, and the helpfulness of these programs is limited by the volume of food they can provide. These programs also require minimum resources to participate, which many of the people in need do not have. Fourth, these programs place a greater burden on women, who are often responsible for their family's food provision, and the programs have low return for the time invested. Overall, Power (1999) takes issue with how well the sustainable-food-systems consider class: the sustainability concerns of the upper class are irrelevant to the poor, who are concerned about the immediate need for their next meal. She notes that "most poor people - who are economically as well as politically marginalized - want to be full participants in society, including its consumerism" (1999, p. 34).

The Good Food Box, a subsidized, alternative fresh produce distribution program discussed earlier in this review, is managed by Foodshare. FoodShare is a non-profit food security organization which started the Good Food Box program in the Greater Toronto Area and empowers other organizations to emulate the model in other regions. Zahra Parvinian, the director of FoodShare's Social Enterprise Programs, confirms Power's (1999) analysis:

Low income families prefer to have the $\$ 12$ in their hands and go to No Frills and choose their own food. This is the reality and we have to accept it. My customers are not very low, low, low income. Because the people [who] have to feed their families they don't need mushrooms. My box [ ...] has mushrooms. People go and get the heavy potatoes and onions and cheapest fruits and vegetables and eat them. (2009) 
Other authors have also noted that low income or racialized people would rather have the agency to buy food from the supermarket than take part in a local food project like a community garden (Guthman, 2008; Agyeman \& Simons, 2012).

Power (1999) states that the sustainable-food-systems approach does not adequately consider issues of class; other authors layer race onto the analysis. Slocum (2006) argues that these community food programs perpetuate white middle-class privilege and exclude racialized groups, and conscious effort must be taken to integrate anti-racist practice into this work. One of the ways that this can be done is changing the fact that racialized people are often "on the table but not at it" - that is, are the subject of discussions, but not necessarily the leaders. An example of the way in which ethno-cultural histories may be overlooked in the sustainable-food-systems approach is provided by Guthman (2008), who observed that organizers were keen to establish urban farms or community gardens, but the African American communities the projects were to target were less enthusiastic in their response and participation. This is because in African American cultural history, growing food and farming was a reminder of past oppression. Reinforcing Slocum's (2006) message, Agyeman and Simons (2012) state that "due to the dominant framing of the discourse from a white, middle class perspective, much of the work to address food vulnerability is being conducted reflects white cultures of food and white histories that may be culturally insensitive to those being served" (p. 94). Both Slocum (2006) and Agyeman and Simons (2012) are careful to note that not all racialized groups are the same and may not perceive community food interventions in the same way. With specific reference to newcomers, Agyeman and Simons (2012) qualify that some underserved minority populations, including refugees, have been found to welcome the opportunity to participate in community food growing in order to gain access to culturally appropriate foods that are not affordable or 
available at the grocery store or farmer's market. African and Latin American groups in US urban centres enjoyed the chance to take part in local food and urban agriculture projects, as it fit with their agrarian and culinary cultural history (Salvidar-Tanaka, 2004).

While Power states that "food solutions will not solve the problem of poverty," (1999, p. 35) she ends by stating that it is imperative to bring together antipoverty and sustainable-foodsystems approaches. The sustainable-food-system's consciousness of human and environmental aspects of food security is important and needed; its contribution to fostering community (among those who are included in the community) and building local and sustainable food systems is valuable. It just cannot stand alone.

Interventions under the antipoverty approach are needed in order to afford immigrants the minimum resources that allow them to decide whether they would like to engage in programs under the sustainable-food-systems approach. Koç and Welsh (2002), in their discussion of immigrant identity and food, remind us that:

Membership, in the modern nation state involves experiences of inclusion, empowerment, entitlement, rights, comforts or quality of life. In this sense, integration, the ability of an individual or a social group to utilise and contribute free of systemic barriers to every dimension of economic, social, cultural and political activities in the society, becomes an equally important component of identity formation. (p. 3)

Some projects are making an effort to marry the environmental and justice aspects of food security, and while there have been blunders, it does not mean that the sustainable-foodsystems approach is completely inappropriate for addressing the needs of low-income immigrants. Baker (2005) assessed farmers markets in two low-income, predominantly immigrant, neighbourhoods in Toronto, Ontario. She called for further theoretical and practical research into subsidies, incentives, and policy support that may allow for the marriage of social justice and environmental sustainability approaches to addressing food security through farmers markets. Johnston and Baker (2005) call upon Community Food Security organizations to scale 
up and out in order to influence change to structural concerns including unequal distribution of wealth, state capacity, and industrial agriculture.

Other calls for action target both the economic aspects of the antipoverty approach and the food focus of the sustainable-food-systems approach. Toronto Public Health (2006), putting emphasis on adequacy of food alongside public health and environmental sustainability considerations, has pointed out that Canada does not have a coordinated government food policy, and that "in Canada, policies affecting food security are multi-jurisdictional, fragmented and for the most part uncoordinated" (p. 126). The UN Special Rapporteur on the Right to Food also highlighted the piecemeal nature of Canada's food policy. While a number of policies touch upon food security related issues, none provide an overarching, interdepartmental view of the issues. He argues that the policies work independently of each other without coordination of goals. Furthermore, some provinces have adopted antipoverty strategies, but the Special Rapporteur emphasized that none of the provinces have adopted a food strategy. Food policy councils at the municipal level have been important for encouraging dialogue among stakeholders and take a multi-faceted view of food. Stakeholders such as farmers and industry have also taken initiatives; it is now time for the government to work with the various levels of government and the stakeholders to establish a national right to food strategy (De Schutter, 2012).

At the moment, community organizations such as food banks are shouldering the burden of helping immigrants who find themselves to be food insecure, and other research and nonprofit organizations such as urban agriculture programs and food education centres are leading the way with innovative approaches to increasing the environmental sustainability and healthiness of food in communities (Riches, 2002; Koç, MacRae, Desjardins, Roberts, 2008; 
World Crops Project, n.d.). The literature points to a need for the government to introduce a national right to food policy that will connect these disparate players, as well as coordinate provincial and municipal level involvement. A national right to food policy would be an opportunity to marry the antipoverty approach and the sustainable-food-systems approach in order to ensure physical and economic access to adequate and acceptable food in Canada.

\subsection{Limitations}

Both food security and immigration are complex topics requiring interdisciplinary approaches, drawing from sociology, geography, nutrition, and other areas. The literature on these topics is also plentiful, and there are studies that have not been included in this review. The goal of this review was to explore what literature exists on challenges to food security for immigrants, and so has included literature to the extent necessary to demonstrate important themes in the literatureuntil a saturation point was reached. Reviews with much narrower scope, for example only one of the components of food security for immigrants from a certain ethnicity would be more conducive to including every published document on a topic, and are a good complement to larger-scope reviews.

\subsection{Implications for practice and research}

A number of recommendations at the community, municipal, provincial, and federal levels have been put forward in the literature and have been mentioned throughout this review. Such changes, however, will have limited effectiveness if they are not coordinated. The literature repeatedly points towards the need for a national strategy on food that would strengthen the work being conducted by civil society organizations. A federal department or agency must take 
responsibility and accountability for food security across the country, rather than a number of different departments taking on various aspects of food security in a disjointed manner. Under a national strategy, work can be done to bring together both the antipoverty and sustainable-foodsystems approaches to tackle poverty and food insecurity for immigrants while being conscious of the environment and human health. An effort should also be made to include immigrants in the leadership of any strategy, so that immigrants will not only be "on the table," but also at it.

Additionally, while action needs to be taken in both the realms of anti-poverty and sustainable-food-systems, this may ultimately be fruitless for immigrants if the issues of discrimination, prejudice, and racism are not also addressed. Discriminatory attitudes in employment and housing, as well as towards the sale, preparation, and consumption of ethnic foods are other areas in which both government and practitioners have roles to play. For example, interventions could include education about multicultural foods and campaigns to build intercultural understanding, especially for children, who have strong influence over what their family members eat.

Based on the current literature, there are a number of gaps that future research can explore or build upon. In terms of adequacy and acceptability, it would be insightful for researchers to explore dietary patterns of immigrants who move to smaller urban centres or rural settings. While most of Canada's immigrants move to major metropolitan centres, some choose to move to relatively more remote environments, where there may not be other people from their home country, and where traditional ingredients would be harder to access than in cities with a critical mass of immigrants. Studies could explore whether dietary acculturation takes place more quickly, how immigrants feel about it, and what the health outcomes are. 
Spanning across all of the components of food security, studies should investigate to what extent the experiences of newcomers in different immigrant classes vary. Commonly, studies will focus on immigrants from a certain ethnic group, who are usually low-income and are living in a certain city. It may seem intuitive that economic immigrants would be more likely to be food secure than other immigrant classes, but this may not necessarily be the case, as Galabuzi (2008) highlights when he notes that there has been an increase in use of food banks by highly educated newcomers. There is a need for empirical research on food security and immigration class to inform planning for future immigration, which will largely be focused on economic immigrants.

Few studies have focused on food security for immigration classes that start with temporary residence but then can transition into permanent residence and citizenship, for example, international students. Brown, Edwards, and Hartwell (2009) begin to fill this gap through their study of international postgraduate students in England, but further research into the experiences of this group would be valuable. In this vein, another class that has not been the focus of existing studies is live-in caregivers. The unique environment they live in-the home of their Canadian resident employers — and their roles which often involve preparing food, would be valuable to study to determine how this affects food security. While not eligible to transition to permanent residence, migrant workers in Canada under the Seasonal Agricultural Worker Program also face unique and often difficult living and working conditions. There have been reports of exploitation of both live-in caregivers and migrant farm workers, which some program changes have sought to investigate, and so future studies could look into the extent to which food security is negatively affected by long hours, living conditions, employers' rules, and other factors associated with the design of the programs. 
Because the issue of food security for immigrants is so multifaceted, changes to policy on immigration, poverty-reduction, and food security all affect food security for immigrants. Research on policy changes at the federal, provincial, and municipal levels should all be continually researched, as should a national food strategy if it comes to light, in order to monitor and evaluate for how they affect food security for immigrants.

Further research is needed on the effectiveness of community gardening, collective kitchens, and other hands-on community programs on food security for immigrants. Existing literature suggests that these activities offer social and personal benefits, but may not improve food security, and that some immigrant groups may be opposed to such programs because of cultural histories. Research into the usage of these programs and when they would be appropriate and effective for immigrants would help inform future interventions.

\subsection{Conclusion}

Food security is important for physical and mental health, as well as for contributing to a positive sense of identity and belonging. Many newcomers in Canada, however, are food insecure, which is a serious concern for a country that relies so heavily upon immigration for growth of both our population and economy. The World Food Summit drew international attention to food security, and Canada's Action Plan on Food Security set out commitments to achieve domestic food security, but the literature demonstrates that immigrants, more than ten years later, still face numerous challenges with the availability, accessibility, adequacy, acceptability, and agency of food. In terms of availability, the literature indicates that immigrants face particular challenges with securing enough income for food as well as housing and other costs. Geographic distance to desirable and affordable food is a consideration, though in addition to conventional channels for 
buying food, creative alternate channels are increasing access to food for immigrants. As immigrants spend time in Canada, a number of factors influence the adequacy of their diets, which can have unhealthy implications. And while immigrants may choose to eat some Western foods, they often also continue to value traditional foods, highlighting the need for culturallyacceptable food and nutrition education. The programs that address food insecurity for immigrants can be considered through the antipoverty and sustainable-food-systems approaches, and efforts should be taken to marry the two, for example under the framework of a national food strategy. This review of the immigration and food security literature has highlighted problems, but has also included recommendations. As changes are made to immigration, food security, and related policies, the literature should grow to fill identified gaps and build on the rich body of existing scholarship. 


\section{REFERENCES}

Access Alliance. (n.d.). Research bulletin 2: Health impacts of employment and income insecurity faced by racialized groups. Retrieved from http://accessalliance.ca/content/ launch-working-rough-living-poor-report

Agriculture and Agri-Food Canada. (1998). Canada's action plan for food security. Ottawa, ON: The Government of Canada. Retrieved from http://www.agr.gc.ca/misb/fsecseca/pdf/action_e.pdf

Agyeman, J., \& Simons, B. L. (2012). Re-imagining the local: Scale, race, culture and the production of food vulnerabilities. In S. Dooling \& G. Simon (Eds.), Cities, nature and development: The politics and production of urban vulnerabilities (pp. 85-100). Farnham, UK: Ashgate Publishing Co.

Anchondo, T. (2010). Neigborhood Deprivation, neighbourhood acculturation, and the retail food environment in a U.S.-Mexico border urban area (Master's thesis). Retrieved from ProQuest Dissertations \& Theses. (Publication number 1477768).

Apparicio, P., Cloutier, M.-S., \& Shearmur, R. (2007.) The case of Montreal's missing food deserts: evaluation of accessibility to food supermarkets. International Journal of Health Geographics, 6(4).

Ayala, X. G., Baquero, B., \& Kilinger, S. (2008). A systematic review of the relationship between acculturation and diet among Latinos in the United States: Implications for future research. Journal of the American Dietetic Association, 108, 1330-1344

Baker, L. (2005). Farmers' markets in low-income neighbourhoods: Confronting the dilemma between social justice and environmental sustainability. Presented at the Social Research in Organic Agriculture Symposium. Guelph, Ontario. Retrieved from http://organicagcenter.ca/Docs/SocialScienceConferences/2005_Lauren_Baker.pdf

Bayanzadeh, M. (2008). Changes in food habits among Farsi and Dari-speaking immigrant women in British Columbia, Canada (Master's thesis). Retrieved from http://summit.sfu.ca/item/8997

Beaulac, J., Kristjansson, E., \& Cummins, S. (2009). A systematic review of food deserts, 19662007. Preventing Chronic Disease, 6(3), 1-10. Retrieved from http://www.cdc.gov/pcd/ issues/2009/jul/08_0163.htm

Behjat, A. (2012). A comparative investigation in measuring food access: Food deserts in urban setting (Master's thesis). 
Bertrand, L., Therien, F., \& Cloutier, M.-S. (2008). Measuring and mapping disparities in access to fresh fruits and vegetables in Montreal. Canadian Journal of Public Health, 99(1), 610.

Bidwell, S. (2009). Food Security: A review and synthesis of themes from the literature. Paper prepared for Programme Area Four Community and Public Health Christchurch, Canterbury District Health Board. Retrieved from http://www.ana.org.nz/documents/ FoodSecurityReview_090827.pdf

Bowen, R., L. \& Devine, C. M. (2011). "'Watching a person who knows how to cook, you'll learn a lot'. Linked lives, cultural transmission, and the food choices of Puerto Rican girls. Appetite, 56, 290-298.

Brink, S. (2001). Lack of food security: Focussed literature review and research framework (Human Resources Development Canada Working Paper W-01-4E). Retrieved from http://publications.gc.ca/collections/Collection/MP32-28-01-4E.pdf

Brown, L., Edwards, J., \& Hartwell, H. (2010). A taste of the unfamiliar. Understanding the meanings attached to food by international postgraduate students in England. Appetite, 54, 202-207.

Burkot, I., Burr, L., \& Lac, J. (2009). Putting a price tag on healthy eating in Toronto. In C. Palassio \& A. Wilcox (Eds.), The edible city: Toronto's food from farm to fork (pp. 148153). Toronto, ON: Coach House Books.

Burns C. (2001). Food insecurity in Somali women living in Australia. Proceedings of the Nutrition Society of Australia, 25, S71.

Burns, C. (2004). A review of the literature describing the link between poverty, food insecurity and obesity with specific reference to Australia. Prepared for Physical Activity Unit, Food Insecurity Program, Victorian Health Promotion Foundation. Retrieved from http://www.ana.org.nz/documents/CateBurnspoverty foodsecurityandobesity.pdf

Campbell, R. (2011). The Experiences of Immigrants Seeking Healthcare in Toronto (Master's thesis). Retrieved from https://tspace.library.utoronto.ca/bitstream/1807/31411/13/ Campbell_Ruth_201111_MSc_Thesis.pdf

Canada Mortgage and Housing Corporation. (2007). Canadian Housing Observer 2007. Ottawa, ON: Canada Mortgage and Housing Corporation.

Centre for Culture Ethnicity and Health. (2008). New arrivals, nutrition and food security literature review 2008. Prepared as part of the New Hope Foundation Food Access Project Report. Retrieved from http://www.maribyrnong.vic.gov.au/ Files/LiteratureReviewNHFProjectFINAL.pdf 
Centre for Studies in Food Security. (2012). Food security defined. Retrieved from http://www.ryerson.ca/foodsecurity/definition/index.html

Chaufan, C., Constantino, S., \& Davis, M. (2012): 'It's a full time job being poor': understanding barriers to diabetes prevention in immigrant communities in the USA. Critical Public Health, 22(2), 147-158.

Chávez, N., Telleen, S., \& Kim, Y. O. R. (2007). Food insufficiency in urban Latino families. Journal of Immigrant and Minority Health, 9(3), 197-204.

Che, C. (2009). Immigrant settlement and the use of food banks. Esurio: Journal of Hunger and Poverty, 1(2), 34-45.

Citizenship and Immigration Canada. (2010). Facts and figures - Immigration overview: Permanent and temporary residents. Retrieved from http://www.cic.gc.ca/english/ resources/statistics/ facts2010/permanent/02.asp

Citizenship and Immigration Canada. (15 June 2010a). News release - Federal, provincial and territorial governments agree to improve Canada's immigration system (Press release). Retrieved from http://www.cic.gc.ca/english/department/ media/releases/2010/2010-0615.asp.

Citizenship and Immigration Canada. (2012). Speaking notes for The Honourable Jason Kenney, P.C., M.P. Minister of Citizenship, Immigration and Multiculturalism: Address to the Empire Club. Retrieved from http://www.cic.gc.ca/english/department/media/ speeches/2012/2012-05-25.asp

Crawford, S., \& Kalina, L. (1997). Building food security through health promotion: Community kitchens. The Journal of the Canadian Dietetic Association, 58(4), 197-201.

Daily Bread Food Bank. (2011). Who's hungry: Profile of hunger in the GTA. Retrieved from http://www.dailybread.ca/wp-content/uploads/2011/09/WhosHungryReport2011WEB.pdf

Dave, J. M., Evans, A. E., Saunders, R. P., Watkins, K. W., \& Pfeiffer, K. A. (2009). Associations among food insecurity, acculturation, demographic factors, and fruit and vegetable intake at home in Hispanic children. Journal of the American Dietetic Association, 109(4), 697-701.

Delisle, H. (2010). Findings on dietary patterns in different groups of African origin undergoing nutrition transition. Applied Physiology, Nutrition, and Metabolism, 35(2 ), 224-228.

DeSchutter, O. (2012). Statement following visit to Canada from 6 to 16 May 2012. Retrieved from http://www.srfood.org/images/stories/pdf/officialreports /201205_canadaprelim_en.pdf 
Dharod, J. M., Croom, J., Sady, C. G., \& Morrell, D. (2011). Dietary intake, food security, and acculturation among Somali refugees in the United States: Results of a pilot study. Journal of Immigrant \& Refugee Studies, 9(1), 82-97.

Dilley, M., \& Boudreau, T. E. (2001). Coming to terms with vulnerability: A critique of the food security definition. Food Policy, 26(3), 229-247.

Dinour, L. M., Bergen, D., \& Yeh, M. (2007). The food insecurity-obesity paradox: A review of the literature and the role food stamps may play. Journal of the American Dietetic Association, 107(11), 1952-1961.

Dubowitz, T., Acevedo-Garcia, D., Salkeld, J., Lindsay, A. C., Subramanian, S. V., \& Peterson, K. E. (2007). Lifecourse, immigrant status and acculturation in food purchasing and preparation among low-income mothers. Public Health Nutrition, 10(4), 396-404.

Engler-Stringer, R., \& Berenbaum, S. (2005). Collective kitchens in Canada: A review of the literature. Canadian Journal of Dietetic Practice and Research, 66(4), 246-251.

Food and Agriculture Organization of the United Nations. (1996). Home page. World Food Summit, Rome, Italy. Retrieved from http://www.fao.org/wfs/index_en.htm

Food and Agriculture Organization of the United Nations. (1996a). Rome Declaration on World Food Security. World Food Summit, Rome, Italy. Retrieved from http://www.fao.org/ wfs/index_en.htm

Food Banks Canada. (2011). Hunger Count: A comprehensive report on hunger and food bank use in Canada, and recommendations for change. Retrieved from http://www.foodbankscanada.ca/ getmedia/dc2aa860-4c33-4929-ac36fb5d40f0b7e7/HungerCount-2011.pdf.aspx

Fox, M. K., Hamilton, W., \& Lin, B-H (Eds.). (2004). Effects of food assistance and nutrition programs on nutrition and health: Volume 3, literature review (Food Assistance and Nutrition Research Report No. 19-3). Prepared for Rural Economics Division, Economic Research Service, U.S. Department of Agriculture. Retrieved from http://ageconsearch.umn.edu/bitstream/33863/1/fa041903.pdf

Franzen, L., \& Smith, C. (2009). Acculturation and environmental change impacts dietary habits among adult Hmong. Appetite, 52(1), 173-83.

Friendly, A. (2008). Towards food security policy for Canada's social housing sector. Canadian Policy Research Network Report.

Friesen, J. (19 June 2012). Canada to raise language bar. The Guardian. Retrieved from http://www.guardian.co.uk/education/2012/jun/19/canada-to-raise-language-bar 
Galabuzi, G.-E. (2008). Social exclusion: Socio-economic and political implications of the racialized gap. In M. A. Wallis \& S.-M. Kwok (Eds.), Daily struggles: The deepening racialization and feminization of poverty in Canada (pp. 81-93). Toronto, ON: Canadian Scholars' Press Inc.

Gallegos, D., Ellies, P., \& Wright, J. (2008). Still there's no food! Food insecurity in a refugee population in Perth, Western Australia. Nutrition \& Dietetics, 65(1), 78-83.

Ghosh, S. (2012). Everyday lives in vertical neighbourhoods: Exploring Bangladeshi residential spaces in Toronto. In H. Bauder (Ed.), Immigration and settlement: Challenges, experiences, and opportunities (pp. 227-246). Toronto, ON: Canadian Scholars' Press.

Goldring, L., Berinstein, C. \& Bernhard, J.K. (2009). Institutionalizing precarious migratory status in Canada. Citizenship Studies, 13(3), 239-265.

Guendelman, M. D., Cheryan, S. \& Monin, B. (2011). Fitting in but getting fat: Identity threat and dietary choices among U.S. immigrant groups. Psychological Science, 22(7), 959967.

Gurnett, J. (2010). Finding a place to call home: The challenge of housing security for immigrants in Alberta. Canadian Issues, Fall 2010, 100-103. Montreal, QC: Association for Canadian Studies.

Guthman, J. (2008). Bringing good food to others: Investigating the subjects of alternative food practice. Cultural Geographies, 15, 431-447.

Hadley, C., Patil, C. L., \& Nahayo, D. (2010). Difficulty in the food environment and the experience of food insecurity among refugees resettled in the United States. Ecology of Food and Nutrition, 49(5), 390-407.

Hadley, C., \& Sellen, D. (2006). Food security and child hunger among recently resettled Liberian refugees and asylum seekers: a pilot study. Journal of Immigrant and Minority Health, 8(4), 369-75.

Hamelin, A.-M., Mercier, C., \& Bédard, A. (2011). Needs for food security from the standpoint of Canadian households participating and not participating in community food programmes. International Journal of Consumer Studies, 35(1), 58-68.

Harris, C. E., \& Shepherd, C. (2007). Food security, learning, and culture: Bridging the responsibility gap in public schools (pp. 129-144). In C.C. Parrish, N.J. Turner, S.M. Solberg (Eds.), Setting the kitchen table: Food security, culture, health and resilience in coastal communities. New York, NY: Nova Science Publishers Inc.

Health Canada. (2007). Canadian community health survey, cycle 2.2, nutrition (2004): Incomerelated household food security in Canada (H164-42/2007E-PDF). Retrieved from 
http://www.hc-sc.gc.ca/fn-an/surveill/nutrition/commun/income_food_sec-sec_alimeng.php

Hiebert, D., Germain, A., Murdie, R., Preston, V., Renaud, J., Rose, D., ... Murnaghan, A.M. (2006). The housing situation and needs of recent immigrants in the Montreal, Toronto, and Vancouver CMAs: An overview. Ottawa: Canada Mortgage and Housing Corporation.

Hill, B. G., Moloney, A. G., Mize, T., Himelick, T., \& Guest, J. L. (2011). Prevalence and predictors of food insecurity in migrant farmworkers in Georgia. American Journal of Public Health, 101(5), 831-833.

Houle, R., \& Schellenberg, G. (2008). Remittance behaviours among recent immigrants in Canada (Statistics Canada publication no. 11F0019M No. 312). Ottawa, ON: Statistics Canada. Retrieved from http://www.statcan.gc.ca/pub/11f0019m/11f0019m2008312eng.pdf

Hulchanski, J. D. (1997). Immigrants and access to housing: How welcome are newcomers to Canada? Summary of Keynote Presentation to the "Housing and Neighbourhoods" Workshop, Metropolis Year II Conference. Retrieved from http://mbc.metropolis.net/ assets/uploads/files/wp/2008/WP08-01.pdf

Human Resources and Skills Development Canada. (2012). Indicators of well-being in Canada: Canadians in context - Immigration. Retrieved from http://www4.hrsdc.gc.ca/ .3ndic.1t.4r@-eng.jsp?iid=38

Husbands, W. (1998). Born in Canada... Or not: Immigration status and food bank assistance in the Greater Toronto Area. Daily Bread Food Bank. Retrieved from http://ceris.metropolis.net/Virtual\%20Library/other/husbands1/husbands1.html

Johnston, J., \& Baker, L. (2005). Eating outside the box: FoodShare's Good Food Box and the challenge of scale. Agriculture and Human Values, 22(3), 313-325.

Kelley, N., \& Trebilcock, M. (2010). The making of the mosaic: A history of Canadian immigration policy $\left(2^{\text {nd }}\right.$ ed.). Toronto, ON: University of Toronto Press.

Kirkpatrick, S. I., \& Tarasuk, V. (2007). Adequacy of food spending is related to housing expenditures among lower-income Canadian households. Public Health Nutrition, 10(12), 1464-1473.

Kirkpatrick, S. I., \& Tarasuk, V. (2010). Assessing the relevance of neighbourhood characteristics to the household food security of low-income Toronto families. Public Health Nutrition, 13(7), 1139-1148.

Kittler, P. G., \& Sucher, K. P. (2004). Food and culture (4 ${ }^{\text {th }}$ ed.). Belmont, CA: Wadsworth/Thomson Learning. 
Koç, M., \& Bas, J.A. (2012). Canada's Action Plan on Food Security: The interactions between civil society and the state to advance food security in Canada. In R. MacRae \& E. Abergel (Eds.), Health and sustainability in the Canadian food system: Advocacy and opportunity for civil society. Vancouver, BC: UBC Press.

Koç, M., MacRae, R., Desjardins, E., \& Roberts, W. (2008). Getting civil about food: The interactions between civil society and the state to advance sustainable food systems in Canada. Journal of Hunger \& Environmental Nutrition, 3(203), 122-144.

Koç, M., \& Welsh, J. (2002). Food, foodways and immigrant experience. Paper written for the Multiculturalism Program, Department of Canadian Heritage at the Canadian Ethnic Studies Association Conference, Halifax. Retrieved from http:/www.canada.metropolis.net/ events/ethnocultural/publications/aliments_e.pdf

Kwok, S., Mann, L., Wong, K., \& Blum, I. (2009). Dietary habits and health beliefs of Chinese Canadians. Canadian Journal of Dietetic Practice and Research, 70(2), 73-80.

Kwok, S. W-H. (2006). Dietary habits, health beliefs and quality of life among ChineseCanadians (Master's thesis). Retrieved from ProQuest Dissertations \& Theses. (Publication number MR34574).

Larsen, K., \& Gilliland, J. (2008). Mapping the evolution of 'food deserts' in a Canadian city: supermarket accessibility in London, Ontario, 1961-2005. International Journal of Health Geographics, 7(16).

Larson, N. I., \& Story, M. T. (2011). Food insecurity and weight status among U.S. children and families: A review of the literature. American Journal of Preventive Medicine, 40(2), 166173.

Lawrence, G. (2007). Review of community food security literature and future directions for addressing community food insecurity in North Minneapolis. Neighborhood Planning for Community Revitalization Report 1248. Retrieved from http://www.cura.umn.edu/ publications/catalog/npcr-1248

Lessa, I., \& Rocha, C. (2009). Nourishing belonging: Food in the lives of new immigrants in T.O. In C. Palassio \& A. Wilcox (Eds.), The edible city: Toronto's food from farm to fork (pp. 148-153). Toronto, ON: Coach House Books.

Lessa, I., \& Rocha, C. (forthcoming). Regrounding in infertile soil: Food insecurity in the lives of new immigrant women.

Lister, N. M. (2007). Placing food: Toronto's edible landscape. In J. Knechtel (Ed.), FOOD (pp. 148-185). Alphabet City Series. Cambridge, MA: MIT Press. Retrieved from http://www.ryerson.ca/ foodsecurity/projects/urbandesign/Nina\%20Marie\% 20Lister\%20paper.pdf 
Lv, N., \& Cason, K. L. (2004). Dietary pattern change and acculturation of Chinese Americans in Pennsylvania. Journal of the American Dietetic Association, 104(5), 771-778.

Martin Prosperity Institute. (2010). Food deserts and priority neighbourhoods in Toronto. Martin Prosperity Insights. Retrieved from http://martinprosperity.org/images/stories/ $\mathrm{jmc} / \mathrm{cache} / \mathrm{mpi}$-food-deserts-and-priority-neighbourhoods-in-toronto.pdf

Maryns, N. (2008). Access and access barriers to getting food stamps: A review of the literature. Food Research and Action Center. Retrieved from http://frac.org/wpcontent/uploads/2009/09/fspaccess.pdf

Maxwell, D. \& Wiebe, K. (1998). Land tenure and food security: A review of concepts, evidence, and methods. Land Tenure Center University of Wisconsin-Madison Research Paper 129.

Maxwell, S. \& Smith, M. (1993). Household food security: A conceptual review. Retrieved from http://www.ifad.org/hfs/tools/hfs/hfspub/hfs_1.pdf

McIntyre, L. \& Tarasuk, V. (2002). The social determinants of health: Food security as a determinant of health. Summary based on papers and presentations prepared for The Social Determinants of Health Across the Life-Span Conference. Retrieved from http://www.phac-aspc.gc.ca/ph-sp/oi-ar/08_food-eng.php

Middlebrook, P. J. (2008). Food security: A review of the literature from Ethiopia to India. Retrieved from http://zunia.org/uploads/media/knowledge/fixed_20_03_ 2009_Food\%20Security\%20-\%20Middlebrook\%20-\%20Geopolicity\%20Inc\%20$\% 202008 . p d f$

Murdie, R. (2010). Precarious beginnings: The housing situation of Canada's refugees. Canadian Issues, Fall 2010, 47-51.

National Council of Welfare. (2012). Total welfare incomes. Retrieved from http://www.ncw.gc.ca/m.1p1data@-eng.jsp

Omidvar, R., Richmond, T. (2003). Immigrant settlement and social inclusion in Canada. Laidlaw Foundation's Working Paper Series, 1-23. Toronto, ON: The Laidlaw Foundation.

O’Reilly, S., O’Shea, T., \& Bhusumane, S. (2012). Nutritional vulnerability seen within asylum seekers in Australia. Journal of Immigrant and Minority Health, 14(2), 356-60.

Oster, A., \& Yung, J. (2010). Dietary acculturation, obesity, and diabetes among Chinese immigrants in New York City. Diabetes Care, 33(8), e109.

Patil, C. L., Hadley, C., \& Nahayo, P. D. (2009). Unpacking dietary acculturation among new Americans: Results from formative research with African refugees. Journal of Immigrant and Minority Health, 11, 342-358. 
Park, S.-Y., Paik, H.-Y., Ok, S.-W., Skinner, J.D., \& Spindler, A. A. (2003). Mothers ' acculturation and eating behaviors of Korean American families in California. Journal of Nutrition Education and Behavior, 35, 142-147.

Park, Y., Neckerman, K., Quinn, J., Weiss, C., Jacobson, J., \& Rundle, A. (2011). Neighbourhood immigrant acculturation and diet among Hispanic female residents of New York City. Public Health Nutrition, 14(9), 1593-600.

Park, Y., Quinn, J., Florez, K., Jacobson, J., Neckerman, K., \& Rundle, A. (2011). Hispanic immigrant women's perspective on healthy foods and the New York City retail food environment: A mixed-method study. Social Science \& Medicine, 73(1), 13-21.

Parvinian, Z. (25 January 2012). A good food social enterprise: Learnings from FoodShare [video file]. Retrieved from http://socialeconomycentre.ca/speakers-series-archivedvideos

Paul, K. (2009). Nourishing place? : Immigrant children's “ethnic food” experiences (Master's thesis). Retrieved from Ryerson Digital Commons. (Paper number 541).

Pouliot, N., \& Hamelin, A.M. (2009). Disparities in fruit and vegetable supply: a potential health concern in the greater Quebec City area. Public Health Nutrition, 12(11), 2051-2059.

Power, E. (1999). Combining social justice and sustainability for food security. In M. Koç, R. MacRae, L. J. A. Mougeot, \& J. Welsh (Eds.), For hunger-proof cities: Sustainable urban food systems (pp. 30-27). Ottawa, ON: International Development Research Centre.

Preston, V., Murdie, R., D’Addario, S., Sibanda, P., Murnaghan, A.M., Logan, J., \& Ahn, M.H. (2011). Precarious housing and hidden homelessness among refugees, asylum seekers, and immigrants in the Toronto Metropolitan Area. CERIS Working Paper No. 87.

Retrieved from http://mbc.metropolis.net/assets/uploads/files/ Precarious_Housing_Toronto_study.pdf

Puhl, E. T. (2011). Food deserts and access to fresh food in low-income San Diego (Master's thesis). Retrieved from ProQuest Dissertations \& Theses. (Publication number 1495372).

Qadeer, M., Agrawal, S., \& Lovell, A. (2010). Evolution of ethnic enclaves in the Toronto Metropolitan Area 2001-2006. Journal of International Migration and Integration, 11(3), 315-339.

Quandt, S. A., Shoaf, J. I., Tapia, J., Hernández-Pelletier, M., Clark, H. M., \& Arcury, T. A. (2006). Experiences of Latino immigrant families in North Carolina help explain elevated levels of food insecurity and hunger. The Journal of Nutrition, 136(10), 2638-2644.

Riches, G. (1999). Reaffirming the right to food in Canada: The role of community-based food security. In M. Koç, R. MacRae, L. J. A. Mougeot \& J. Welsh (Eds.), For hunger-proof cities: Sustainable urban food systems (pp. 203-207). Ottawa, ON: International 
Development Research Centre.

Riches, G. (2002). Food banks and food security: Welfare reform, human rights and social policy. Lessons from Canada? Social Policy \& Administration, 36(6), 648-663.

Riches, G., Buckingham, D., MacRae, R., \& Ostry, A. (2004). Study conducted for FAO in support of the Intergovernmental Working Group on the Elaboration of a set of Voluntary Guidelines for the Realization of the Right to Adequate Food in the context of National Food Security (Food and Agriculture Organization publication IGWG RTFG/INF 4/APP.2).

Rosenmöller, D. J., Gasevic, D., Seidell, J., \& Lear, S. A. (2011). Determinants of changes in dietary patterns among Chinese immigrants: a cross-sectional analysis. International Journal of Behavioral Nutrition and Physical Activity, 8(42).

Ruel, M. T., Garrett, J. L., Hawkes, C., \& Cohen, M. J. (2010). The food, fuel, and financial crises affect the urban and rural poor disproportionately: A review of the evidence. The Journal of Nutrition, 140(1), 170S-176S.

Ruel, M. T., Garrett, J. L., Morris S. S., Maxwell, D., Oshaug, A., Engle, P., ... Haddad, L. (1998). Urban challenges to food and nutrition security: A review of food security, health, and caregiving in the cities. Food Consumption and Nutrition Division International Food Policy Research Institute Discussion Paper 51.

Rush, T. J., Ng, V., Irwin, J. D., Stitt, L. W., \& He, M. (2007). Food insecurity and dietary intake of immigrant food bank users. Canadian Journal of Dietetic Practice and Research, 68(2), 73-8.

Saldivar-Tanaka, L., \& Krasny, M. E. (2004). Culturing community development, neighborhood open space, and civic agriculture: the case of Latino community gardens in New York City. Agriculture and Human Values, 21(4), 399-412.

Sano, Y., Garasky, S., Greder, K. A., Cook, C. C., \& Browder, D. E. (2010). Understanding food insecurity among Latino immigrant families in rural America. Journal of Family and Economic Issues, 32(1), 111-123.

Satia, J. A. (2010). Dietary acculturation and the nutrition transition: an overview. Applied Physiology, Nutrition and Metabolism, 35, 219-223.

Satia, J. A., Patterson, R. E., Kristal, A. R., Hislop, T. G., Yasui, Y., \& Taylor, V.M. (2001). Development of scales to measure dietary acculturation among Chinese-Americans and Chinese-Canadians. Journal of the American Dietetic Association, 101(7), 548-553.

Satia, J. A., Patterson, R. E., Taylor, V. M., Cheney, C. L., Shiu-Thornton, S., Chitnarong, K., \& Kristal, A. R. (2000). Use of qualitative methods to study diet, acculturation, and health 
in Chinese-American women. Journal of the American Dietetic Association, 100(8), 934940.

Satia-Abouta, J., Patterson, R. E., Kristal, A. R., The, C., \& Tu, S.-P. (2002). Psychosocial predictors of diet and acculturation in Chinese American and Chinese Canadian women. Ethnicity \& Health, 7(1), 21-39.

Scharf, K. (1999). A Nonprofit system for fresh-produce distribution: The case of Toronto, Canada. In M. Koç, R. MacRae, L. J. A. Mougeout \& J. Welsh (Eds.). For hunger-proof cities: Sustainable urban food systems (pp. 122-127). Ottawa, ON: International Development Research Centre.

Setia, M., Quesnel-Vallee, A., Abrahamowicz, A., Tousignant, P., \& Lynch, J. (2009). Convergence of body mass index of immigrants to the Canadian-born population: evidence from the National Population Health Survey (1994-2006). European Journal of Epidemiology, 24(10), 611-623

Sharkey, J. R., Johnson, C. M., \& Dean, W. R. (2011). Nativity is associated with sugarsweetened beverage and fast-food meal consumption among Mexican-origin women in Texas border colonias. Nutrition Journal, 10(1), 101.

Slocum, R. (2006). Anti-racist practice and the work of community food organizations. Antipode, 38(2), 327-349.

Slocum, R. (2010). Race in the study of food. Progress in Human Geography, 35(3), 303-327.

Smoyer-Tomic, K. E., Spence, J. C., \& Amrhein, C. (2006). Food deserts in the Prairies? Supermarket accessibility and neighborhood need in Edmonton, Canada. The Professional Geographer, 58(3), 307-326.

Standish, K., Nandi, V., Ompad, D.C., Momper, S., \& Galea, S. (2010). Household density among undocumented Mexican immigrants in New York City. Journal of Immigrant and Minority Health, 12(3), 310-318.

Statistics Canada. (2012). Population growth in Canada: From 1851 to 2061 - Population and dwelling counts, 2011 Census. Census in Brief (98-310-XWE2011003). Retrieved from http://www12.statcan.gc.ca/census-recensement/2011/as-sa/98-310-x/98-310x2011003_1-eng.pdf

Tarasuk, V., \& Reynolds, R. (1999). A qualitative study of community kitchens as a response to income-related food security. Canadian Journal of Dietetic Practice and Research, 60(1), 11-16.

Teelucksingh, C., \& Galabuzi, G.-E. (2007). Working precariously: The impact of race and immigrant status on employment opportunities and outcomes in Canada. In T. Das Gupta, 
C. E. James, R. C. A. Maaka, G.-E. Galabuzi \& C. Andersen (Eds.), Race and racialization: Essential readings (pp. 202-208). Toronto, ON: Canadian Scholars' Press.

Toronto Public Health (2006). Food security: Implications for the early years - Background paper. Toronto, ON: Toronto Public Health. Retrieved from http://www.toronto.ca/ health/children/pdf/fsbp_final.pdf

United Nations Special Rapporteur on the Right to Food. (n.d.). Right to food. Retrieved from http://www.srfood.org/index.php/en/right-to-food

United Way. (2011). Vertical poverty: Poverty by postal code 2. Retrieved from http://www.unitedwaytoronto.com/verticalpoverty/report/introduction/

Vahabi, M., Damba, C., Rocha, C., \& Montoya, E. C. (2011). Food insecurity among Latin American recent immigrants in Toronto. Journal of Immigrant and Minority Health, 13(5), 929-39.

Vallianatos, H., \& Raine, K. (2008). Consuming food and constructing identities among Arabic and South Asian immigrant women. Food, Culture and Society: An International Journal of Multidisciplinary Research, 11(3), 355-373.

Varghese, S., \& Moore-Orr, R. (2002). Dietary acculturation and health-related issues of Indian families in Newfoundland. Canadian Journal of Dietetic Practice and Research, 63(2), 72-79.

Walia, H. (2010). Transient servitude: migrant labour in Canada and the apartheid of citizenship. Race \& Class, 52(1), 71-84.

Walker, R. E., Keane, C. R., \& Burke, J. G. (2010). Disparities and access to healthy food in the United States: A review of food deserts literature. Health \& Place, 16(5), 876-884.

Welsh, J. (1998). Food Security, Health and the Immigrant Experience. Toronto, ON: Final Report. Retrieved from http://www.ryerson.ca/content/dam/foodsecurity/projects/ immigrationsettlement/Welsh1998.pdf

Worby, E. (2010). Address unknown: The temporality of displacement and the ethics of disconnection among Zimbabwean migrants in Johannesburg. Journal of Southern African Studies, 36(2), 417-431.

World Crops Project. (n.d.). About. Retrieved from http://worldcropsproject.posterous.com/ pages/about

World Health Organization. (2012). Food Security. Retrieved from http://www.who.int/trade/ glossary/story028/en/ 